Syntax Idea: p-ISSN: 2684-6853 e-ISSN: 2684-883X

Vol. 3, No. 7, Juli 2021

\title{
PENGARUH RISIKO SEBAGAI PENENTU MINAT PEMBELIAN PELANGGAN SHOPEE DI JAKARTA
}

\section{Peter Bramanto, Rodhiah}

Universitas Tarumanagara (UNTAR) Jakarta, Indonesia

Email: peterbramanto7@gmail.com,rodhiah@fe.untar.ac.id

\begin{abstract}
Abstrak
Minat pembelian didasari oleh pengalaman penggunaan dan keinginannya pada suatu produk sebagai bentuk tingkah laku konsumen yang berkeinginan membeli produk. Tujuan dari penelitian ini adalah untuk menguji pengaruh negatif risiko produk terhadap minat pembelian pelanggan Shopee di Jakarta. Pengaruh negatif risiko waktu terhadap minat pembelian pelanggan Shopee di Jakarta. Pengaruh negatif risiko sosial terhadap minat pembelian pelanggan Shopee di Jakarta. Populasi populasi adalah suatu wilayah yang di dalamnya terdiri dari karakteristik atau kualitas tertentu yang sudah ditetapkan oleh para peneliti agar bisa dipelajari. Populasi dalam penelitian ini adalah pelanggan Shopee di Jakarta. Sampel pada penelitian ini sebanyak 100 responden dengan menggunakan metode non probability sampling dengan teknik Convenience sampling. Teknik pengumpulan data dengan menyebarkan kuesioner melalui google-form. Teknik analisis data yang digunakan adalah Structural Equation Modeling (SEM), dengan menggunakan Smart PLS 3 sebagai alat untuk menganalisis data. Hasil penelitian menunjukkan bahwa ini adalah risiko produk dapat mempengaruhi minat pembelian secara negatif dan tidak signifikan, risiko waktu dapat mempengaruhi minat pembelian secara negatif dan signifikan demikian juga risiko sosial dapat mempengaruhi minat pembelian secara negatif dan signifikan pada pelanggan Shopee di Jakarta.
\end{abstract}

Kata Kunci: risiko produk; risiko waktu; risiko sosial; minat pembelian.

\section{Abstract}

Minat purchase is based on the experience of use and desire on a product as a form of consumer behavior that wants to buy products. The purpose of this study is to test the negative influence of product risk on Shopee's customer purchase interests in Jakarta. Negative influence of time risk on Shopee customer purchase interest in Jakarta. Negative influence of social risk on Shopee customers' purchase interests in Jakarta. Population is a region in which certain characteristicsof at au quality havebeen established by the researchers in order to be studied. The population in this study was Shopee customers in Jakarta. Samples in this study as many as 100 respondents using non probability sampling method with Convenience sampling technique. Data collection techniques by disseminating questionnaires through google-form. The data analysis technique used is Structural Equation Modeling (SEM), using Smart PLS 3 as a tool to analyze data. The results show that this is a risk that the product can negatively and insignificantly affect the purchase interest, the time risk can negatively and significantly affect the purchase interest as well as

$\begin{array}{ll}\text { How to cite: } & \text { Bramanto, Peter, Rodhiah (2021) Pengaruh Risiko Sebagai Penentu Minat Pembelian Pelanggan } \\ & \text { Shopee Di Jakarta, Syntax Idea, 3(7). https:// doi.org/10.36418/syntax-idea.v3i7.1334 } \\ \text { E-ISSN: } & \text { 2684-883X } \\ \text { Published by: } & \text { Ridwan Institute }\end{array}$


the social risk can negatively and significantly affect the purchase interest in Shopee customers in Jakarta.

Keywords: product risk; time risk; social risk; purchase intention.

\section{Pendahuluan}

Menurut (Stevens, Loudon, \& Wrenn, 2012) mengungkapkan minat pembelian didasari oleh pengalaman penggunaan dan keinginannya pada suatu produk sebagai bentuk tingkah laku konsumen yang berkeinginan membeli produk. Menurut (Kudeshia \& Kumar, 2017) berpendapat bahwa minat pembelian sangat penting bagi suatu marketplace karena dapat menggambarkan kesan dari konsumen. Dari penelitian sebelumnya mengungkapkan bahwa risiko yang dirasakan konsumen akan memiliki dampak negatif pada minat pembelian konsumen (Almousa, 2011).

Dalam penelitian yang dilakukan oleh (Kim \& Lennon, 2013), semakin besar risiko berbelanja di marketplace, maka semakin turun niat beli konsumen terhadap marketplace tersebut. (Akhlaq \& Ahmed, 2015) menemukan bahwa risiko berpengaruh negatif terhadap minat konsumen untuk membeli secara online. Hal ini menunjukkan bahwa minat konsumen untuk membeli secara online ditekan ketika konsumen mengetahui bahwa transaksi tersebut berisiko (Akhlaq \& Ahmed, 2015). Hasil sebelumnya menunjukkan bahwa risiko yang dirasakan berhubungan negatif dengan minat membeli di marketplace, seperti yang ditunjukkan oleh (Zhao, Deng, \& Zhou, 2017) dan (Akhlaq \& Ahmed, 2015). Menurut (Han \& Kim, 2017) meneliti risiko memilki multidimensi yang meliputi keuangan, produk, waktu, keamanan, sosial.

Saat berbelanja online tentu terdapat banyak risiko risiko yang harus dihadapi konsumen. Salah satu contohnya yaitu risiko keuangan. Dalam penelitian (Zhao et al., 2017) risiko keuangan adalah kemungkinan biaya perbaikan yang diperlukan untuk produk yang dibeli. Menurut (Masoud, 2013) mengemukakan bahwa segala bentuk kerugian finansial baik itu melalui penipuan kartu kredit, kualitas produk rendah, dan produk tidak bekerja sesuai dengan yang diharapkan akan memilki efek negative yang kuat pada minat pembelian. Sementara menurut (Almousa, 2011) dan (Dai, 2007), risiko keuangan merupakan salah satu risiko yang dipersepsikan secara negatif akan memengaruhi minat pembelian konsumen.

Ketika membeli produk dalam berbelanja online, konsumen hanya dapat melihat pada informasi yang diberikan oleh penjual. berpendapat salah satu kendala yang harus diatasi oleh pelanggan ketika berbelanja online adalah adanya kemungkinan kecil untuk memeriksa produk secara fisik sebelum melakukan pembelian, Dalam penelitian yang dilakukan oleh (Han \& Kim, 2017) menegaskan bahwa risiko produk berpengaruh negatif terhadap minat pembelian konsumen di pasar online Cina. Oleh sebab itu, risiko produk sangat mempengaruhi minat pembelian.

Saat melakukan belanja online, terkadang konsumen harus menghabiskan waktu untuk mencari barang yang diinginkan. Risiko waktu adalah ketika produk tidak memenuhi tingkat harapan konsumen dan konsumen harus mengembalikan produk untuk pengganti baru (Ariff, Sylvester, Zakuan, Ismail, \& Ali, 2014). Menurut (Dai, 
2007) berpendapat risiko waktu adalah waktu yang dihabiskan konsumen untuk melakukan pembelian dan menunggu produk dikirim. Terkadang, konsumen pergi begitu saja dari situs marketplace tanpa membeli apa pun karena mereka tidak dapat mencari yang diinginkan produk dari marketplace tersebut (Popli \& Mishra, 2015).

Belanja online harus memiliki keamanan yang memadai di marketplace. Hal tersebut bertujuan agar konsumen merasa aman dalam bertransaksi di marketplace. Risiko keamanan diartikan sebagai potensi kerugian karena penipuan atau peretasan online, yang mengekspos keamanan transaksi internet atau pengguna online (Soltanpanah, Shafe, \& Mirani, 2012). Menurut (Adnan, 2014) mengemukakan bahwa kebijakan privasi adalah diperlukan untuk mengurangi risiko keamanan yang dirasakan oleh pelanggan dan dengan demikian dapat meningkatkan minat membeli. Ketika konsumen tidak percaya dengan keamanan marketplace maka konsumen akan enggan untuk membeli produk atau barang pada marketplace tersebut. Hal itu berdampak pada minat pembelian konsumen di marketplace tersebut.

Dalam penelitian yang dilakukan oleh (Shang, Pei, \& Jin, 2017) disebutkan risiko sosial dapat mencegah konsumen melakukan pembelian. Selain itu, risiko sosial dapat berupa rasa takut, terutama dari keluarga dan teman yang tidak menyetujui pembelian yang dilakukan oleh konsumen (Popli \& Mishra, 2015). Ketika ulasan dari keluarga atau teman konsumen tentang produk yang hendak dibeli konsumen tidak baik maka konsumen akan mengurungkan minatnya untuk membeli produk tersebut.

Dari beberapa penelitian sebelumnya, banyak peneliti melakukan penelitiannya pada marketplace atau situs jual beli online di luar negri. Sehingga peneliti tertarik untuk mereplikasikan penelitian tersebut pada pengguna marketplace Shopee di ibukota Jakarta.

\section{Metode Penelitian}

Penelitian didesain sebagai penelitian deskriptif. Sampel penelitian ini adalah konsumen yang pernah atau sedang menggunakan Shopee. Pengumpulan sampling yang digunakan pada penelitian ini ialah dengan teknik non-probability sampling “convenience." Jumlah responden yang diambil oleh peneliti sebanyak 100 responden. Dari jumlah 100 responden yang digunakan dalam penelitian ini, mayoritas responden berjenis kelamin pria (64\%), berusia di antara 21-24 tahun (92\%), Berdomisisli Jakarta Barat (37\%), dan memiliki pekerjaan sebagai seorang pelajar (65\%). Sementara, objek penelitian terdiri dari Risiko produk, Risiko Waktu, Risiko Sosial, dan Minat Pembelian. Indikator pengukuran variabel penelitian ini disajikan pada Tabel 1 berikut ini.

Tabel 1

Indikator Pengukuran Variabel

\begin{tabular}{lcl}
\hline \multicolumn{1}{c}{ Variabel } & Item & \multicolumn{1}{c}{ Sumber } \\
\hline Minat Pembelian & 3 & Diadaptasi dari Abubakar et al. (2016) \\
\hline Risiko produk & 7 & $\begin{array}{l}\text { Diadaptasi dari Shaizatulaqma et al. (2018); } \\
\text { Ashoer dan Said (2016); Masoud (2013). }\end{array}$ \\
\hline Risiko Waktu & 6 & Diadaptasi dari Shaizatulaqma et al. (2018); \\
\hline
\end{tabular}




\begin{tabular}{ccl}
\hline Variabel & Item & \multicolumn{1}{c}{ Sumber } \\
\hline & & $\begin{array}{l}\text { Ashoer } \\
\text { dan Said (2016); Masoud (2013). }\end{array}$ \\
\hline Risiko Sosial & 6 & $\begin{array}{l}\text { Diadaptasi dari Shaizatulaqma } \text { et al. (2018); } \\
\text { Ashoer } \\
\text { dan Said (2016); Masoud (2013). }\end{array}$ \\
\hline
\end{tabular}

Pada penelitian ini semua variabel yang digunakan diukur dengan menggunakan skala Likert yang memiliki 5 poin, dimana angka 1 menyatakan "Sangat Tidak Setuju" dan terakhir angka 5 menyatakan "Sangat Setuju". Pada tahap analisis validitas dan reliabilitas, dari total 22 item tersisa 11 item yang digunakan dalam mengukur variabel Risiko produk, Risiko Waktu, Risiko Sosial, dan Minat Pembelian dikarenakan terdapat beberapa item yang memiliki nilai loading factor dibawah 0,4 (0,7) dan memiliki nilai AVE diatas $0,5(>0,5)$ sehingga dapat disimpulkan bahwa telat memenuhi syarat validitas konvergen dan validitas diskriminan serta Cross Loadings. Terakhir, pada pengujian reliabilitas menyatakan bahwa semua variabel dalam penelitian ini memiliki nilai Composite Reliabilty dan Cronbach's Alpha di atas 0,6 $(>0,6)$. Berarti, semua variabel yang digunakan dalam penelitian tergolong reliabel (Nunan, Malhotra, \& Birks, 2020).

Tabel 2

Hasil Analisis Validitas Konvergen

\begin{tabular}{cc}
\hline Variabel / Dimensi & $\begin{array}{c}\text { Average Variance } \\
\text { Extracted }\end{array}$ \\
\hline Minat Pembelian & 0,749 \\
\hline Risiko Produk & 0,628 \\
\hline Risiko Waktu & 0,721 \\
\hline Risiko Sosial & 0,646 \\
\hline
\end{tabular}

Tabel 3

Hasil Analisis Reliabilitas

\begin{tabular}{ccc}
\hline Variabel & Cronbach's Alpha & Composite Reliability \\
\hline Minat Pembelian & 0,837 & 0,899 \\
\hline Risiko Produk & 0,728 & 0,835 \\
\hline Risiko Sosial & 0,727 & 0,845 \\
\hline Risiko Waktu & 0,641 & 0,836 \\
\hline
\end{tabular}

\section{Hasil dan Pembahasan}

Pada penelitian ini dilakukan juga pengujian path coefficient yang memiliki tujuan agar dapat mengetahui arah serta apakah hubungan variabel dependen dengan variabel independen dinyatakan kuat atau lemah. Di bawah ini merupakan hasil pengujian bootsraping yang ditampilkan dalam bentuk tabel. 
Tabel 4

Hasil Analisis Path Coefficient

\begin{tabular}{cclc}
\hline & $\begin{array}{c}\text { Path } \\
\text { Coefficient }\end{array}$ & t-statistics & $\begin{array}{c}\boldsymbol{p} \text { - } \\
\text { values }\end{array}$ \\
\hline $\begin{array}{c}\text { RisikoProduk } \longrightarrow \text { Minat } \\
\text { Pembelian }\end{array}$ & $-0,134$ & 1,105 & 0,270 \\
\hline $\begin{array}{c}\text { Risiko Waktu } \longrightarrow \text { Minat } \\
\text { Pembelian }\end{array}$ & $-0,176$ & 2,055 & 0,040 \\
\hline $\begin{array}{c}\text { Risiko Sosial } \longrightarrow \text { Minat } \\
\text { Pembelian }\end{array}$ & $-0,245$ & 2,753 & 0,006 \\
\hline
\end{tabular}

Hasil dari pengujian hipotesis yang pertama $\left(\mathrm{H}_{1}\right)$ menunjukan bahwa hipotesis pertama ditolak. Hal tersebut menunjukan bahwa risiko produk tidak dapat menurunkan minat pembelian pelanggan Shopee di Jakarta. Hal ini berbeda dari penelitian sebelumnya oleh (Dai, 2007) yang menyatakan risiko produk berdampak negatif terhadap minat pembelian. Lebih lanjut penelitian (Masoud, 2013) juga menyatakan bahwa risiko produk memiliki pengaruh negatif terhadap minat pembelian yang terjadi di perusahaan belanja online. Hasil dari penelitian sebelumnya oleh (Han \& Kim, 2017) menegaskan bahwa risiko produk secara negatif mempengaruhi minat pembelian konsumen di pasar online.

Shopee merupakan salah satu marketplace yang cukup digemari masyarakat. Hal ini dapat dilihat dari penilain konsumen yang baik terhadap Shopee. Shopee juga menduduki peringkat utama sebagai marketplace dengan data kunjungan terbanyak dibanding marketplace lainnya. Dapat dikatakan bahwa konsumen memiliki minat pembelian yang tinggi pada marketplace Shopee, sehingga risiko produk yang dirasakan oleh konsumen tidak dapat menurunkan minat pembelian pelanggan pada Shopee.

Selanjutnya untuk pengujian hipotesis yang kedua $\left(\mathrm{H}_{2}\right)$ menunjukan bahwa hipotesis kedua tidak ditolak. Hal tersebut berarti bahwa risiko waktu dapat menurunkan minat pembelian pelanggan Shopee di Jakarta. Hasil tersebut sejalan dengan penelitian yang dilakukan oleh (Masoud, 2013) juga menyatakan bahwa risiko waktu memiliki pengaruh negatif terhadap minat pembelian dikarenakan adanya faktor seperti lama waktu estimasi hingga barang tiba hingga membutuhan waktu dalam melakukan pemesanan barang. Hasil dari penelitian yang dilakukan oleh (Dai, 2007) juga menyatakan bahwa risiko waktu juga mempengaruhi minat pembelian yang disebabkan karena faktor lamanya waktu yang dihabiskan oleh seorang konsumen untuk melakukan pembelian. Penelitian lain yang dilakukan oleh Liu et al., tahun 2013 cmenyatakan bahwa risiko waktu memiliki pengaruh negatif terhadap minat pembelian.

Hasil pengujian hipotesis ketiga $\left(\mathrm{H}_{3}\right)$ menunjukan bahwa hipotesis ketiga tidak ditolak. Hal tersebut berarti bahwa risiko sosial memiliki pengaruh negatif dan 
dapat menurunkan minat pembelian pelanggan Shopee di Jakarta. Hal tersebut didukung dengan hasil penelitian dari (Shang et al., 2017) menyatakan bahwa risiko sosial memiliki pengaruh negatif terhadap minat pembelian. Hasil dari penelitian yang dilakukan oleh (Popli \& Mishra, 2015) menyebutkan risiko sosial dapat menurunkan minat pembelian konsumen dikarenakan ketidak setujuan dari lingkungan hidup konsumen. Dalam penelitian DelVecchio dan Smith tahun 2005 menyatakan bahwa risiko sosial telah terbukti dapat menimbulkan tujuan non konsumsi yang dapat berpengaruh mengurangi minat pembelian.

\section{Kesimpulan}

Berdasarkan hasil analisis dan pembahasan, maka dapat dibuat beberapa kesimpulan yaitu Risiko produk tidak memilki pengaruh terhadap minat pembelian pelanggan Shopee di Jakarta. Risiko waktu memilki pengaruh terhadap minat pembelian pelanggan Shopee di Jakarta. Risiko sosial memilki pengaruh terhadap minat pembelian pelanggan Shopee di Jakarta. 


\section{BIBLIOGRAFI}

Adnan, Hooria. (2014). An analysis of the factors affecting online purchasing behavior of Pakistani consumers. International Journal of Marketing Studies, 6(5), 133. Google Scholar

Akhlaq, Ather, \& Ahmed, Ejaz. (2015). Digital commerce in emerging economies: Factors associated with online shopping intentions in Pakistan. International Journal of Emerging Markets. Google Scholar

Almousa, Moudi. (2011). Perceived risk in apparel online shopping: a multi dimensional perspective. Canadian Social Science, 7(2), 23-31. Google Scholar

Ariff, Mohd Shoki Md, Sylvester, Michele, Zakuan, Norhayati, Ismail, Khalid, \& Ali, Kamarudin Mat. (2014). Consumer perceived risk, attitude and online shopping behaviour; empirical evidence from Malaysia. IOP Conference Series: Materials Science and Engineering, 58(1), 12007. IOP Publishing. Google Scholar

Dai, Bo. (2007). The impact of online shopping experience on risk perceptions and online purchase intentions: the moderating role of product category and gender. Google Scholar

Han, Min Chung, \& Kim, Youjeong. (2017). Why consumers hesitate to shop online: Perceived risk and product involvement on Taobao. com. Journal of Promotion Management, 23(1), 24-44. Google Scholar

Kim, Jiyoung, \& Lennon, Sharron J. (2013). Effects of reputation and website quality on online consumers' emotion, perceived risk and purchase intention: Based on the stimulus-organism-response model. Journal of Research in Interactive Marketing. Google Scholar

Kudeshia, Chetna, \& Kumar, Amresh. (2017). Social eWOM: does it affect the brand attitude and purchase intention of brands? Management Research Review. Google Scholar

Masoud, Emad Y. (2013). The effect of perceived risk on online shopping in Jordan. European Journal of Business and Management, 5(6), 76-87. Google Scholar

Nunan, Daniel, Malhotra, Naresh K., \& Birks, David F. (2020). Marketing Research: Applied Insight. Pearson UK. Google Scholar

Popli, Ankita, \& Mishra, Smita. (2015). Factors of perceived risk affecting online purchase decisions of consumers. Pacific Business Review International, 8(2), 4958. Google Scholar

Shang, Qian, Pei, Guanxiong, \& Jin, Jia. (2017). My friends have a word for it: eventrelated potentials evidence of how social risk inhibits purchase intention. Neuroscience Letters, 643, 70-75. Google Scholar 
Soltanpanah, Heirsh, Shafe, Reza, \& Mirani, Vala. (2012). A review of the literature of perceived risk and identifying its various facets in e-commerce by customers: Focusing on developing countries. African Journal of Business Management, 6(8), 2888-2896. Google Scholar

Stevens, Robert E., Loudon, David L., \& Wrenn, Bruce. (2012). Marketing management: text and cases. Routledge. Google Scholar

Zhao, Xiaofei, Deng, Shengliang, \& Zhou, Yi. (2017). The impact of reference effects on online purchase intention of agricultural products: The moderating role of consumers' food safety consciousness. Internet Research. Google Scholar

Copyright holder :

Peter Bramanto dan Rodhiah (2021)

First publication right :

Syntax Idea

This article is licensed under: 